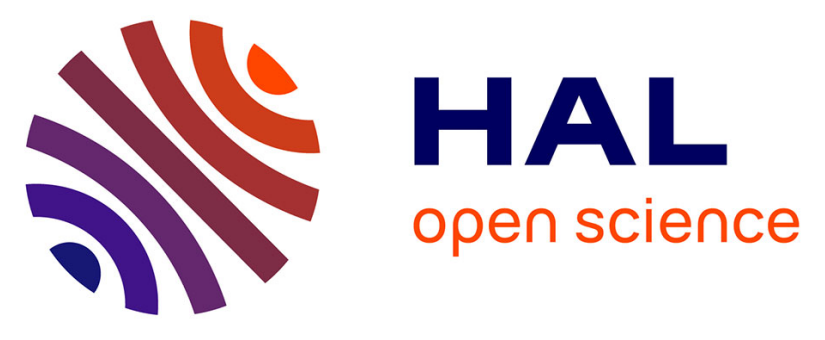

\title{
Do distinct mind wandering differently disrupt drivers? Interpretation of physiological and behavioral pattern with a data triangulation method
}

Guillaume Pepin, Severine Malin, Christophe Jallais, Fabien Moreau, Alexandra Fort, Jordan Navarro, Daniel Ndiaye, Catherine Gabaude

\section{To cite this version:}

Guillaume Pepin, Severine Malin, Christophe Jallais, Fabien Moreau, Alexandra Fort, et al.. Do distinct mind wandering differently disrupt drivers? Interpretation of physiological and behavioral pattern with a data triangulation method. Consciousness and Cognition, 2018, 62, pp.69-81. 10.1016/j.concog.2018.04.006 . hal-01867964

\section{HAL Id: hal-01867964 https://hal.science/hal-01867964}

Submitted on 4 Sep 2018

HAL is a multi-disciplinary open access archive for the deposit and dissemination of scientific research documents, whether they are published or not. The documents may come from teaching and research institutions in France or abroad, or from public or private research centers.
L'archive ouverte pluridisciplinaire HAL, est destinée au dépôt et à la diffusion de documents scientifiques de niveau recherche, publiés ou non, émanant des établissements d'enseignement et de recherche français ou étrangers, des laboratoires publics ou privés. 
1 Title: Do distinct mind wandering differently disrupt drivers? Interpretation of physiological

2 and behavioral pattern with a data triangulation method

3

4 Guillaume Pepin ${ }^{1}$, Séverine Malin ${ }^{2}$, Christophe Jallais ${ }^{1}$, Fabien Moreau ${ }^{1}$, Alexandra Fort ${ }^{1}$, 5 Jordan Navarro $^{2,4}$, Daniel Ndiaye ${ }^{3}, \&$ Catherine Gabaude ${ }^{1}$

6

71 Univ Lyon, IFSTTAR, TS2, LESCOT, F-69675, LYON, France

82 Laboratoire d'Etude des Mécanismes Cognitifs, Université de Lyon, Bron, France

93 Université Paris-Est, COSYS, LEPSIS, IFSTTAR, F-77447 Marne-la-Vallée, France

104 Institut Universitaire de France, Paris, France

11

12

13 Keywords: Mind-wandering, Task-unrelated thoughts, Driving simulation, Heart rate, Ocular 14 behavior, Neuroergonomics 
In absence of a specific task demand, it is extremely difficult to prevent our minds to wander (Corballis, 2013). Even during our daily living activities, our minds commonly escape from the here and now (Killingsworth \& Gilbert, 2010). Mind-wandering, also known as off-task thoughts, is a remarkable evolutionary achievement allowing to plan self-relevant events or remember memorable contents. But although this state can be beneficial, it can also be detrimental by impairing current task performance (McVay \& Kane, 2009). For this reason, it is damaging for tasks requiring sustained and divided attention, as can be the driving activity. Recent findings seemed to be indicating that all mind wandering may not be equal (Burdett, Charlton, \& Starkey, 2016; Galera et al., 2012; Golchert et al., 2017). The present paper intends to delve into characteristics of off-task thoughts to assess their respective detrimental impacts on driving.

\subsection{Attention and driving}

Since a decade now, epidemiological studies have indicated that drivers' inattention and distraction accounted for 25 to 50\% of road accidents (Mosedale, Purdy, \& Clarkson, 2004). Inattention and distraction have been described as states with different impacts on drivers while they would be responsible for an equivalent part of accidents (Galera et al., 2012). Although different taxonomies have been proposed to better understand and distinguish these states and their respective impacts on drivers, they are still inconsistently defined. Indeed, the relationship between them remains unclear, generating serious difficulties for researchers to study and measure same phenomenon. In the present study, despite the taxonomy of (Regan \& Strayer, 2014), inattention is defined as a state in which attention have endogenously slid from the main activity to thoughts and feelings. However, inattention does not really exist per se; our mind is always focused on something but not necessarily on the main activity and people are not all time aware of where their thoughts are focused. Considering the constant fluctuations of people's mind and conscious, it could be hard to spot the different moments when they are no longer focused on the main activity. These fluctuations go from being fully on-task to being in a mind-blanking state (Ward \& Wegner, 2013) by going through a wide range of inattentive states. This is why inattention is not a homogeneous state and can be differently critical for safe driving.

Inattention gathers several states including Mind-Wandering (MW) which corresponds to a shift in the content of thoughts away from an ongoing task to self-generated thoughts and feelings (Smallwood \& Schooler, 2015). But even with a specific definition of MW, it remains difficult to unbendingly categorize driver's thoughts and, more broadly, driver's states. Indeed, MW is by nature an unprompted, constantly fluctuating state, which presence varies spontaneously over time (Chaparro, 2015). MW does not correspond to all off-task thoughts but to self-generated and stimulus-independent thoughts (SITUTs). For example, thinking to the next step of our trip is not considered as MW because it is related to the driving task. But in a different context, it could be considered as MW showing the difficulty to categorize driver's thoughts. Assessing the presence of MW is even more essential since it represents between 30 
(Berthié et al., 2015; Bixler \& D'Mello, 2014; Killingsworth \& Gilbert, 2010). It is also a recurring phenomenon in driving: four drivers out of five declare having being aware of their wandering thoughts during their last journey and felt being in this state for more than a third of the time (Berthié et al., 2015). The occurrence of MW is also negatively correlated with task demand (Braboszcz \& Delorme, 2011; He, Becic, Lee, \& McCarley, 2011). As an ubiquitous state whether in driving or in everyday life, MW can have serious consequences.

\subsection{Consequences of MW behind the wheel}

MW, as defined across studies, has adaptive and useful roles in our life such as autobiographical planning, creative thinking or self-reflection (Baird, Smallwood, \& Schooler, 2011; Mooneyham \& Schooler, 2013; Smallwood et al., 2011). But it is a detrimental state in driving since it interferes with the driving activity. MW with high disrupting content multiplies by 2.12 the risk to be responsible for a road accident (i.e., 1.98 for sleep deprivation, 1.76 for psychotropic drug use and 1.06 for MW with little disrupting content; (Galera et al., 2012). This higher crash risk could be explained by the perceptual decoupling (Smallwood, McSpadden, \& Schooler, 2008) which could underlie the looked-but-failed-to-see phenomenon (Brown, 2005). Perceptual decoupling corresponds to the capacity for the mind to flexibly disengage attentional processes from perception (Smallwood \& Schooler, 2015). Besides, changes in the brain during MW (Christoff, Gordon, Smallwood, Smith, \& Schooler, 2009; Greicius, Krasnow, Reiss, \& Menon, 2003; Raichle et al., 2001) will affect driver behavior.

MW might degrade the driver's control of the vehicle, with a decrease of speed microregulations and larger lane departures (Lemercier et al., 2014). In addition, it seems to increase the reaction time variability and decreases safety distances (Yanko \& Spalek, 2014). MW also might cause a failure to scan the environment because of a visual attention focused narrowly on the road ahead (He et al., 2011). Although people control the location of where they are looking, it is physically impossible for drivers to control or manipulate fixations and saccades (Rayner, 1998). Such lack of control suggests that gaze behavior might provide a relevant behavioral marker of directed attention and seems responsive to MW (He et al., 2011). In sum, perceptual decoupling leads to changes in driver's behavior leading to higher frequency of errors, which may explain the important role of MW on the occurrence of accidents. MW also leads to changes in drivers' physiological functions. It increases heart rate (Smallwood et al., 2004) and leads to changes in several cardiac markers (Ottaviani et al., 2014). It seems therefore appropriate to investigate MW by using behavioral and physiological measurements.

But, in the light of previous results (Galera et al., 2012), it seems that all kind of mindwandering are not equal and could generate different level of risk for drivers. Consequently, it seems appropriate to investigate factors involved in the dangerousness of MW. Indeed, a wandering mind can suffer from a higher crash risk because of a highly disrupting content or not. In the driving context, to further improve road safety, it is therefore relevant to investigate how our attention is drawn from the main activity and how the kind of thought would differently affect drivers and potentially increase their level crash risk. 
96 As already said, inattention is difficult to assess regarding its spontaneous fluctuation. And this state seems even more complicated to study since it is not uniform. Indeed, inattention corresponds to Task-Unrelated Thoughts (TUTs) gathering all the kinds of inattentive thoughts such as Task-Related Interferences (TRIs) or Stimulus-Independant Task-Unrelated Thoughts (SITUTs) (Lemercier et al., 2014; Stawarczyk, Majerus, Maj, Van der Linden, \& D'Argembeau, 2011). SITUTs correspond to the typical MW experience. In the past decade, MW has been popularized and drawn scientists' attention to better understand the stream of thoughts and consciousness. Research on this topic has seen a substantial increase boosted by many studies (for a review, see Smallwood \& Schooler, 2015). Mind-wandering is generally conceptualized as a two steps state. The onset phase represents the initial moment when the mind drifted away from task focus to off-task focus. The maintenance phase represents the cognitive experience and duration of the off-task episode (Smallwood, 2013). This last phase could be maintained due to failures in attentional disengagement which might be due to the attentional tunneling phenomenon (Dehais, Causse, \& Tremblay, 2011). During the onset phase of MW, a first self-generated drift of attention toward an off-task focus occurs. Then, cognitive resources are drawn to sustain the MW state. Different kinds of thought can be generated from these resources.

It appears that each thought owns specific features considering its willfulness (intentional vs. self-generated), awareness (aware vs. unaware), content: temporality (past, present or future), emotional valence (positive vs. negative) etc... Internal mental task as well as mentally solving problems can not be considered as MW at once; thoughts features should be dug deeper to classify the kind of thought although all inattentive thoughts belong to the TUTs category. For example, intentional TUTs such as Problem Solving Thoughts (PSTs) (Golchert et al., 2017), and unintentional TUTs such as MW are different states and are characterized by distinctive neural networks (Smith et al., 2006). Moreover, at a brain level, what researchers call MW (unaware and unintentional) arise with an activation of the default mode network (DMN) alone while intentional off-task thoughts such as PSTs arise from an activation of the DMN with a region of grey matter associated with intentional off-task thoughts (Golchert et al., 2017). For this reason, the impact of intentionality of TUTs has to be assessed to explain the disruptiveness of MW (Seli, Ralph, Konishi, Smilek, \& Schacter, 2017). Moreover, MW experience are unaware (during the onset phase) and self-generated (not primed by an external element) while PSTs are aware and intentional. Those features shape the kind of thought (Spronken, Holland, Figner, \& Dijksterhuis, 2016) and the intentionality of MW seems promising to explain different impacts of TUTs (Kopp, D’Mello, \& Mills, 2015) on drivers' behavior and physiological signals, and more broadly on their respective dangerousness. Indeed, intentional and unintentional off-task thoughts are underpinned by distinct neural networks which could explain different level of dangerousness (Smith et al., 2006). Considering links between MW and oculometric indicators (He et al., 2011) and the fact that intentional processes are often regulated by executive control allowing operators to regulate their state, it could then generate a higher level of gaze fixity or larger lane departures for MW than for PSTs. More gaze fixity or lane departures might reflect a higher level of dangerousness for the driver. But, when 
137 investigating MW or off-task thoughts in general, studies can suffer from a too low

138 experimental control because of the multiplicity of features, thoughts and experiences lived by

139 participants. It is therefore necessary to be cautious on this particular regard and improve the 140 experimental control to avoid biases (Smallwood \& Schooler, 2015).

In 2003, Parasuraman introduced a new interdisciplinary field called "neuroergonomics," which aspires to be the best methodological approach for studying the "brain at work". The interaction between ergonomics and neurosciences would improve our understanding of the brain in action and our ability to study internal states. Using objective and direct data drew from neurosciences or related to it (Parasuraman, 2003) would allow to enhance knowledge about internal mental states. By highlighting behavioral and/or physiological pattern of MW, the first stone of a detection model of MW would be laid. Indeed, it is already possible to use datamining methodology on objective data to detect an internal mental state (Liang, Reyes, \& Lee, 2007; Liang \& Lee, 2014). Previous authors managed to build and prove the worth of a detection model of distraction. In the same vein, a detection model could be proposed to detect MW while driving. Considering that notable behaviors such as eyes-off the road are not sensitive enough to spot inattention, the search of MW indicators should focus on physiological data and on leaner behavior, almost impossible to control. To achieve this goal, a data triangulation methodology has been set up, whereby we use the confluence of behavioral, physiological and self-report data (J. W. Schooler \& Schreiber, 2004) to improve the experimental control, essential to study MW (Smallwood \& Schooler, 2015). Such method allow validating each dimension as measures of "what they say they measure" (Seth, Dienes, Cleeremans, Overgaard, \& Pessoa, 2008).

Given a detection model of disruptive MW as a long-term objective, we need to expand our understanding of MW, delving the characteristics underlying this state. More specifically, we need to understand if the intentionality of TUTs will affect the disruptiveness of MW. To do so, it is relevant to investigate how the kind of thought differentially disrupts driver's behavior (speed, lane departure) and impact physiological signatures. Subjective data on the other hand allow classifying drivers' state and then make comparisons between on-task and off-task moments using physiological and behavioral metrics. It could therefore be possible to better understand the most deleterious aspect of MW in order to detect it during risk situations while permitting the mind to wander when the driving demand is low.

170 There are three main objectives for the present study. First, it intends to assess the physiological and behavioral correlates of Task-Unrelated Thoughts (TUTs) in driving. Second, it intends to explain the differences between intentional (PSTs) and unintentional (MW) off-task thoughts by making a clear distinction between these kinds of thought to better describe their respective impacts on drivers. Third, with the use of a data triangulation methodology, it aims at highlighting different physiological and behavioral signatures for Problem-Solving Thoughts 


\section{MATERIALS AND METHODS}

178

179

180

181

182

183

184

185

186

187

188

189

190

191

192

193

194

195

196

197

198

199

200

201

202

203

204

205

206

207

208

209

210

211

212

213

214

215

216

\subsection{Participants}

Twenty healthy volunteers (10 males; age $34.15 \pm 11.93$ ) consented to participate in the present study. Before starting the experiment, participants were asked about their health status and none declared cardiovascular disease, attentional or sensorial deficit or any comprehension difficulty were included. All of them reported normal or corrected to normal visual acuity and had been holders of a valid driving license for at least 3 years. All participants gave written consent and received 30 euros for their participation. No participant declared having consumed coffee, alcohol or drug the day of experiment.

\subsection{Experimental design}

One repeated measure (temporal-windows: $[-5.5 \mathrm{~s} ;+5.5 \mathrm{~s}]$ ) and one within-subject factor (the kinds of thought: MW and PSTs) were studied.

In order to evaluate the impact of the kind of thought on behavioral and physiological measurement, two tasks were proposed. For the first one, participants were told to keep their attention on the driving task as much as possible and to indicate whenever they realized that their attention had drifted away to MW. For that they had to push the headlights close to selfreport (SR) their MW episodes. MW was defined for participants as "when you are thinking about something that has nothing to do with driving. For example, something you were doing before the experiment, something you will do later or thinking about people or a particular person" (Burdett et al., 2016). Each time they pushed the headlights, participants declared unintentional off-task thoughts. Participants then had to focus on the driving activity. The second task consisted in asking participants to find innovations on specific topics while driving (for instance: "how to improve mobility for disabled or older persons"). Innovations should not exist yet and had to be as sophisticated as possible. Participants had to say "Stop" when they considered their ideas were elaborated enough. Such task allowed generating Problem Solving Thoughts (PSTs) whose characteristics are close to MW except that thoughts are intentional. Moreover, participants were not asked to think about a personal goal or issue to control the content of thought (temporal orientation and distance, emotional valence...). By saying "Stop" at the end of each PSTs phase, participants declared having intentional off-task thoughts.

In each PST phase, participants were given instructions about a specific area (e.g., educational system, sport etc.). They then had to elaborate one innovation. In each scenario, 3 topics were proposed and all participants were asked to reflect upon 6 different innovations during the whole experiment. Instructions about each innovation were previously recorded and broadcasted in the simulator cabin at the beginning of each PST phase. The end of each PST phase was also announced by instructions broadcasted in the cabin. Then, a new MW phase started and participants were reminded they had to push the headlights whenever they realized that their mind wandered. Each MW phase lasted $1 \mathrm{~min}$ and a half and each PST phase lasted 2 minutes. All participants had the same order of conditions presentation which was MW-PSTMW-PST-MW-PST-MW for both scenarios. Considering the changing aspect of MW, alternating tasks appeared to be the more realistic way to create an enabling environment for 
the emergence of MW. For this reason four phases of self-reported MW were alternated with three phases of reflections on innovations (PSTs). Each scenario began and ended with a MW phase.

The really nature of the two tasks that participants were asked to perform would lead to a different number of events for each kind of thought. During MW phases, participants were able to self-report several MW episodes while they had to think about one innovation during the PST phase.

Moments when participants self-reported their wandering thoughts or said "stop" after reflecting upon innovations were considered as "events". Physiological and behavioral data were compared before and after self-report events and before and after participants said "stop" after thinking on innovations. Therefore, it was possible to compare temporal window designated as inattention interval (before) and temporal window designated as an attentive interval (after) (He et al., 2011).

\subsection{Material \& Apparatus}

\subsubsection{Driving simulator}

The driving simulator used in this experiment was a Peugeot 308 cabin (length $=4.27 \mathrm{~m}$; width $=1.81 \mathrm{~m}$ ) surrounded by seven video projection screens (covering a total angular space of $270^{\circ}$ and vertical angular size of $47.5^{\circ}$ ). Participants drove in a straight line interrupted by right and left curves in an urban residential zone. It was a two-way country road with only few vehicles coming from the opposite direction of the participant vehicle so as to enable the emergence of MW (He et al., 2011). To remain coherent with Braboszcz \& Delorme, 2011 and He et al., (2011), the driving environment was purposely refined to encourage MW. The road contained long straights lines interrupted by right and left curves. Participants completed 2 scenarios of 12 min using the same visual base. They had a break between the two scenarios to avoid any fatigue effect.

\subsubsection{Cardiac measurement}

Heart rate was measured using 3 electrodes (Biopac, MP150 using Bionomadix transmitters) during the whole experiment. The positive electrode was placed under the last left rib, the negative electrode on the manubrium of the sternum, and the ground electrode on the right side, just on top of the hip. In a test phase, it has been checked that this positioning satisfies the main conditions to collect correct cardiac signal during driving: compromising with the length of the wires and avoiding a noisy signal due to muscular activity.

Heart Rate (HR) values were computed using equations provided by Roy, (2015) and illustrated by Pepin et al., (2017). From the cardiac signal, several time-domain indices bringing information about heart rate variability have been calculated from IBI such as the Root Mean Square Successive Differences of NN intervals (RMSSD) and proportion of the number of 
256 Eye movements were sampled at $30 \mathrm{~Hz}$ with an eye-tracking device (Tobii Glasses v1). To analyze the visual information gathering while driving, a gaze fixity rate indicator has been designed. The gaze fixity was present if at least $90 \%$ of eye absolute positions were contained in a visual angle area of $2^{\circ}$ for more than $1 \mathrm{~s}$. So, the gaze fixity is a binary indicator and then can take only 2 values ( 1 when there is gaze fixity and 0 when there is not). An algorithm has been set up to transform the absolute position towards gaze fixity for each time step. In order to convert the absolute gaze position into the gaze fixity, such process has been carried out for each time step for each participant throughout a sliding window conversion. This algorithm, coded 1 if $90 \%$ of the 29 next gaze absolute positions (corresponding to $1 \mathrm{sec}$ ) were contained in a $2^{\circ}$ of visual angle area. The gaze fixity rate is the mean of gaze fixity across all events of each condition.

\subsubsection{Driving data}

The driving simulator provided several driving measures such as the speed (in kilometer per hour), the lateral position compared to the center of the lane (in meter) and the steering wheel angle (in degree). Measures of driving performance were sampled at a mean rate of $60 \mathrm{~Hz}$ and were synchronized with cardiac data through the BioPac MP150 and with the Tobii Glasses 1.

\subsubsection{Questionnaire}

Participants had to fill in a questionnaire about personal details (age, gender, driving habits, driving experience, attentional and auditory disorder, drug consumption etc...).

After each scenario participants had to fill a survey about the content of MW and PSTs. Items enlighten the temporal focus of MW (past, present or future), its emotional valence and its subjective impact on driving performance. For each proposal, participants had to indicate the number of wandering thoughts they remembered having for each dimension.

\subsection{Procedure}

Prior to the experiment, participants were informed about the content of the experiment and asked to give their informed consent. They were also aware that they could stop the experiment at any time. Cardiac electrodes were affixed. Then, participants sat in the simulator cabin and a 5 min baseline measurement of HR was recorded. A short training session on the driving simulator was performed to familiarize him/herself with the simulator and the driving environment. Then, participants were equipped with the eye-tracker glasses and the calibration phase started. Prior to the beginning of the first scenario, participants were instructed about PSTs and MW conditions. Participants were asked to maintain the car speed at $70 \mathrm{Km} / \mathrm{h}$ and stay in the center of the lane. After the first scenario, they completed the «Mind Wandering » questionnaire about their attentional focus and the content of their thoughts. After a break, they performed the second scenario. Then, they completed the MW questionnaire once again and the survey about personal information. Finally, at the very end of the experiment, a debriefing session was performed to explain the purpose of the study and answer participants' questions. 
294 Physiological and behavioral data were compared before and after MW moments and before 295 and after PST moments. Such comparisons allow to make within-subject comparisons. It 296 assumes that participants were in a MW state or were reflecting upon innovation before 297 participants SR their wandering thoughts or said stop after reflecting upon innovation. 298 Moreover, it assumes that they were refocused on the main activity (i.e., driving) after it. 299 Considering temporal windows used in a previous study(He et al., 2011), [-5.5s; 0s] and $300[0 \mathrm{~s} ;+5.5 \mathrm{~s}]$ temporal windows were chosen here to study and compare respectively off-task 301 (PSTs or MW) and on-task thoughts. This decision is based on assumptions that in the 5.5 302 seconds prior to the event participants were in MW or focus on their PSTs while theirattention 303 in the 5.5 seconds following the event was redirected towards driving. These assumptions seem 304 more likely to be verified than with the use of temporal windows used in other studies (He et 305 al., 2011).

306 Statistical analyses were conducted to address two experimental questions in particular:

1) What are the behavioral and physiological correlates of inattentive thoughts towards driving?

2) Is it possible to distinguish problem solving thoughts and stimulus-independent and task-unrelated thoughts (MW)?

311 The first step was to check distributions normality using the Kolmogorov-Smirnov test. 312 Depending on this result, ANOVAs, Wilcoxon were conducted to compare 1) changes between 313 before and after, 2) changes between before and after according to the kind of thought and t314 tests were conducted to compare 3) differences during before and after according to the kind of 315 thought. 


\section{RESULTS}

317 Overall, 285 events were collected across all conditions and through all participants. Grand 318 mean responses have been computed by averaging data over all events. Different numbers of 319 events from cardiac and oculometric metrics have been removed resulting in different numbers 320 of event suitable for analysis. It appears that $13.68 \%$ of eye-tracking data, $7.37 \%$ of cardiac data 321 and $0 \%$ of driving data have been removed. Events were removed from analyses either because 322 temporal windows were overlapping other events or because data were unsuitable for analysis. 323 It is also possible that participants did not said "stop" because did not complete their innovation 324 within the allocated time. The number of each event for each variable is presented in Table 1.

325 Table 1: Number of usable events, mean, standard deviation and p-value of the difference for each variable. MW $326=$ Mind-wandering; PST = Problem-Solving Thought

\begin{tabular}{|c|c|c|c|c|c|c|c|c|c|c|c|c|c|c|c|c|c|c|}
\hline & \multicolumn{9}{|c|}{ MW } & \multicolumn{9}{|c|}{ PST } \\
\hline & $\begin{array}{c}\text { Number of } \\
\text { participant } \\
\text { with usable } \\
\text { data }\end{array}$ & $\begin{array}{c}\text { Mean of } \\
\text { usable } \\
\text { events by } \\
\text { participant }\end{array}$ & $\begin{array}{c}\text { SD of } \\
\text { usable } \\
\text { events by } \\
\text { participant }\end{array}$ & $\begin{array}{l}\text { Sum of } \\
\text { usable } \\
\text { events }\end{array}$ & $\begin{array}{c}\text { Mean for } \\
{[-5,5 ; 0]} \\
\text { time- } \\
\text { window }\end{array}$ & $\begin{array}{c}\text { SD for } \\
{[-5,5 ; 0]} \\
\text { time- } \\
\text { window }\end{array}$ & $\begin{array}{c}\text { Mean for } \\
{[0 ;+5,5]} \\
\text { time- } \\
\text { window }\end{array}$ & $\begin{array}{c}\text { SD for } \\
{[0 ;+5,5]} \\
\text { time- } \\
\text { window }\end{array}$ & $p$-value & $\begin{array}{c}\text { Number of } \\
\text { participant } \\
\text { with usable } \\
\text { data }\end{array}$ & $\begin{array}{c}\text { Mean of } \\
\text { usable } \\
\text { events by } \\
\text { participant }\end{array}$ & $\begin{array}{c}\text { SD of } \\
\text { usable } \\
\text { events by } \\
\text { participant }\end{array}$ & $\begin{array}{l}\text { Sum of } \\
\text { usable } \\
\text { events }\end{array}$ & $\begin{array}{c}\text { Mean for } \\
{[-5,5 ; 0]} \\
\text { time- } \\
\text { window }\end{array}$ & $\begin{array}{c}\text { SD for } \\
{[-5,5 ; 0]} \\
\text { time- } \\
\text { window }\end{array}$ & $\begin{array}{c}\text { Mean for } \\
{[0 ;+5,5]} \\
\text { time- } \\
\text { window }\end{array}$ & $\begin{array}{c}\text { SD for } \\
{[0 ;+5,5]} \\
\text { time- } \\
\text { window }\end{array}$ & $p$-value \\
\hline Gaze Fixity & 20 & 10,00 & 4,68 & 200 & 0,52 & 0,15 & 0,41 & 0,19 & $<.001$ & 15 & 2,40 & 1,82 & 48 & 0,46 & 0,24 & 0,41 & 0,22 & $>.05$ \\
\hline Heart Rate & 20 & 9.55 & 4,02 & 191 & 72,51 & 13,72 & 73,51 & 14.40 & $<.001$ & 17 & 2,35 & 1,57 & 47 & 73.25 & 15.00 & 74.13 & 15.74 & $<.01$ \\
\hline Speed & 20 & 11,1 & 5,17 & 222 & 70,72 & 2.26 & 71,46 & 2.65 & $<.05$ & 19 & 2,70 & 1,45 & 54 & 72,52 & 4,14 & 72.27 & 4.38 & $>.05$ \\
\hline
\end{tabular}

\subsection{Questionnaires}

328 Participants declared having more future-oriented (47.64\%) than past-oriented (13.19\%) 329 thoughts $(\mathrm{T}=56, \mathrm{z}=3.89, p<.0001)$. Considering thoughts emotional valence, participants 330 declared having less negative thoughts $(15 \%)$ than neutral $(44.47 \%)(\mathrm{T}=74, \mathrm{z}=3.69, p<.001)$ 331 or positive thoughts $(40.53 \%)(\mathrm{T}=88, \mathrm{z}=3.29, p<.001)$.

\subsection{Comparisons Before/After for TUTs}

Cardiac data

334 The only significant result among cardiac measurement concerned Heart Rate (HR) which was 335 higher after $(\mathrm{m}=73.34, \quad \mathrm{SD}=13.29) \quad$ TUTs than before $(\mathrm{m}=72.33, \quad \mathrm{SD}=12.53)$ $336(F(1,19)=11.57, p<.01)$. RMSSD and pNN50 metrics appeared non-significant with 337 Wilcoxon tests $(p>.05)$.

Eye-tracking data

339 The difference in gaze fixity rate between before $(m=0.495, \mathrm{SD}=0.25)$ and after $340(\mathrm{~m}=0.511, \mathrm{SD}=0.17)$ gave rise to a significant effect in the $[-5.5 \mathrm{~s} ;+5.5 \mathrm{~s}]$ temporal window $341 \quad(F(1,19)=10.15, p<.01)$.

\subsubsection{Driving data}

343 A trend appeared for the vehicle speed is different between before $(\mathrm{m}=71.07, \mathrm{SD}=2.36)$ and $344 \operatorname{after}(\mathrm{m}=71.83, \mathrm{SD}=3.14)$ and it gave rise to a significant effect in the $[-5.5 \mathrm{~s} ;+5.5 \mathrm{~s}]$ temporal 345 window $(F(1,19)=3.84, p=.065)$. 
346 The lateral position and the steering wheel angle comparisons appeared both non-significant $347(p>.05)$.

\subsection{Comparisons Before/After for MW and PST}

\subsubsection{Cardiac data}

HR appeared significantly different between before $(m=72.51, \mathrm{SD}=13.72)$ and after $351(\mathrm{~m}=73.51, \mathrm{SD}=14.40)$ for the MW condition: $F(1,19)=10.85, p<.01$.

352 HR averaged across all participants in the $[-5.5 \mathrm{~s} ;+5.5 \mathrm{~s}]$ temporal window according to the kind 353 of thought is presented in Figure 1.

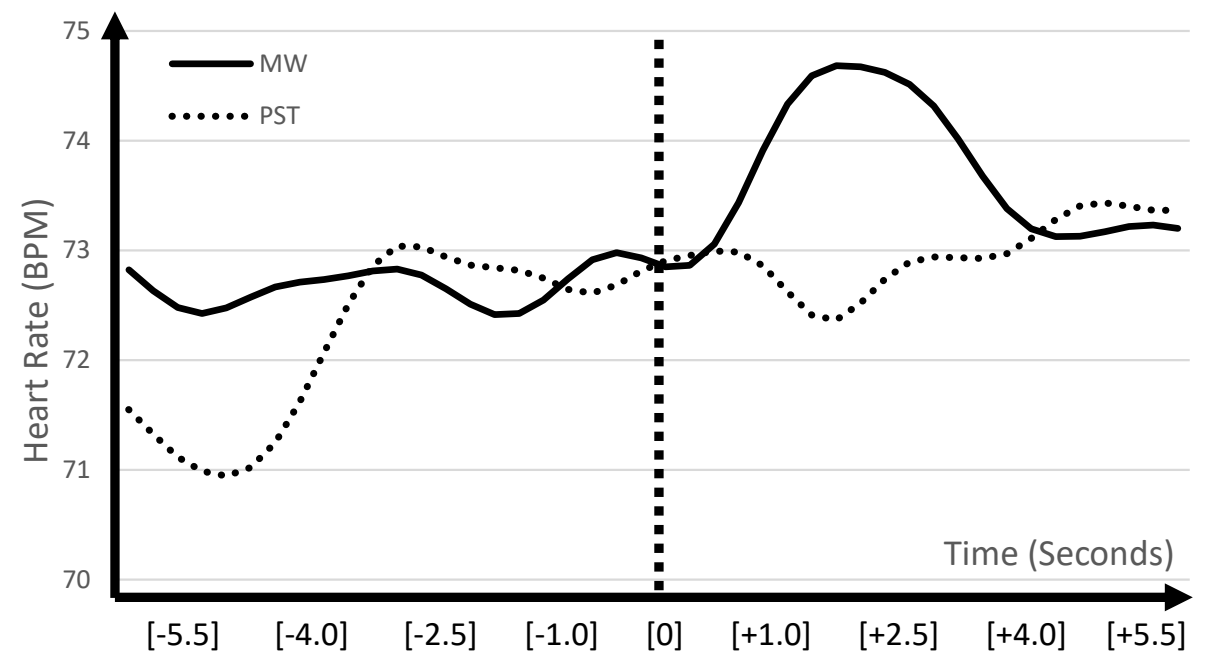

Figure 1: Evolution of grand mean heart rate (obtained from raw data) within 11 seconds surrounding the event, data depict MW and PST conditions.

357 For PST, a trend appeared for HR between the inattentive phase $(\mathrm{m}=73.25, \mathrm{SD}=15.00)$ and the attentive phase $(\mathrm{m}=74.13, \mathrm{SD}=15.74)$, for the PST thoughts $(F(1,19)=3.109, p=.093)$.

360 The gaze fixity rate was higher during $\mathrm{MW}(\mathrm{m}=0.522, \mathrm{SD}=0.15)$ than during attentive 361 moments $(\mathrm{m}=0.413, \mathrm{SD}=0.19) \quad$ in the $[-5.5 \mathrm{~s} ;+5.5 \mathrm{~s}]$ temporal window $362(F(1,19)=10.95, p<.01)$.

363 Conversely, the difference in the gaze fixity rate for the PST condition in the [-5.5s; $+5.5 \mathrm{~s}]$ 364 temporal window was not significant $(F<1)$.

365 Gaze fixity rates according to the type of tasks are presented in Figure 2 and Figure 3. 


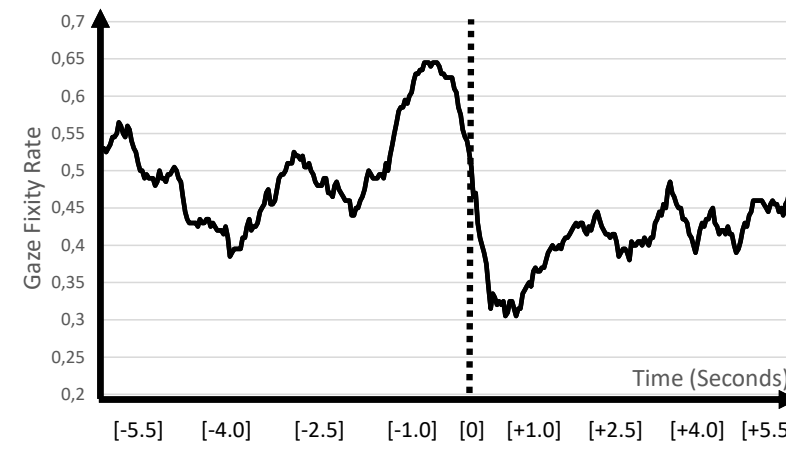

Figure 2: Grand mean of gaze fixity in the 11 seconds surrounding a MW self-report. Data averaged over 200 events

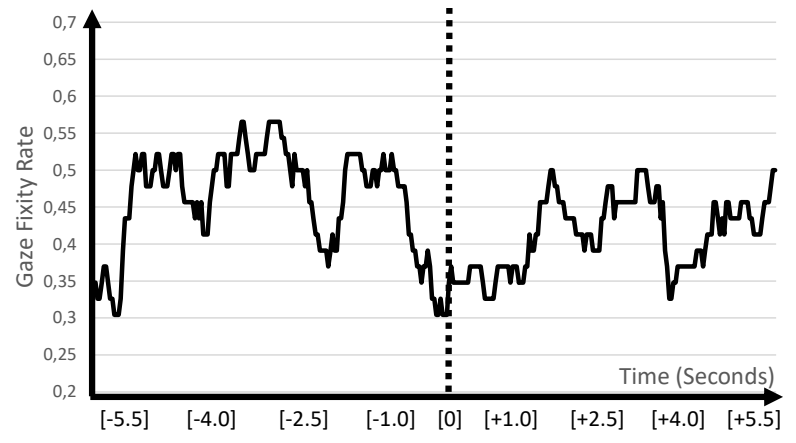

Figure 3: Grand mean of gaze fixity in the 11 seconds surrounding a PST event. Data averaged over 46 event

\subsubsection{Driving data}

Concerning MW results, differences concerning lateral position as well as the steering wheel angle appeared non-significant $(\mathrm{p}>.05)$ between before and after MW.

A trend appeared for the car speed between before $(\mathrm{m}=70.72, \mathrm{SD}=2.56)$ and after for the MW $(F(1,19)=4.01, p=.060)$.

372 Concerning PST, neither the lateral position, nor the steering wheel angle, nor the vehicle speed was significantly different between before and after moments.

374 Car speeds according to the kind of task are presented in Figure 4.

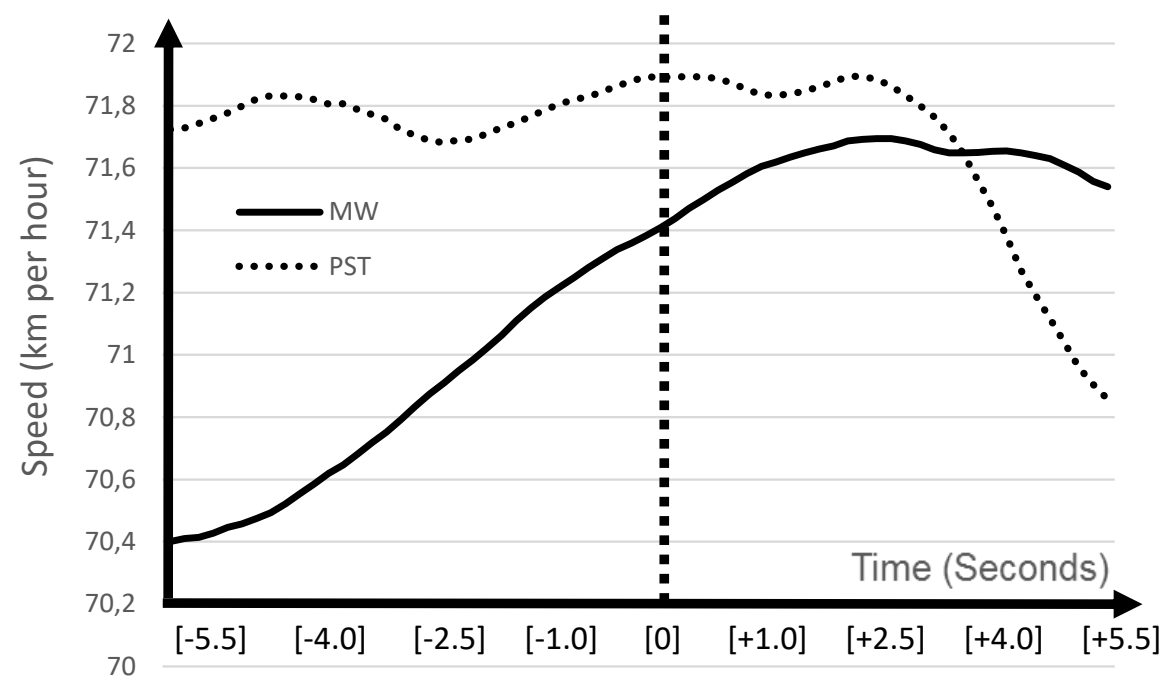

Figure 4: Grand mean of vehicle speed in the 11 seconds surrounding events, data depict MW and PST conditions. 


\section{DISCUSSION}

The objectives of the present study was to (1) make a clear distinction between intentional $($ Problem Solving Thoughts $=$ PSTs $)$ and unintentional $(\mathrm{MW})$ off-task thoughts, $(2)$ assess the physiological and behavioral signatures of TUTs (both MW and PSTs) and (3) compare MW and PST. Participants had to 1) Self-Report (SR) their wanderings thoughts when they realized their mind drifted away from driving and 2) intentionally generate PST. For this, one repeated measure (temporal-windows: $[-5.5 \mathrm{~s} ;+5.5 \mathrm{~s}]$ ) and one within-subject factor (the kinds of thought: MW and PSTs) were studied.

\subsection{MW features}

Concerning the features of thoughts that participants declared (MW condition), the prospective bias showed in previous studies has been replicated: $48 \%$ of SR thoughts were future-oriented while only $13 \%$ where past-oriented. These findings support the view of an important role of MW to enable anticipation and planning of personally relevant future goals (Baird et al., 2011; Stawarczyk, Cassol, \& D'Argembeau, 2013). Proportion of interfering thoughts related to the task (39\% in the present study) is also consistent with prior findings (Gonçalves et al., 2017; Stawarczyk et al., 2011). Moreover, considering links between temporality and valence, the high proportion of neutral or positive thoughts (85\%) is also consistent with the prospective bias highlighted here. Results obtained from questionnaires indicate that 1) MW own a useful planning role in our lives and 2) that participants generated ecological off-task thoughts comparable to MW generated during other studies.

\subsection{TUTs signatures}

Physiological data analysis showed that Heart Rate (HR) was significantly lower during TaskUnrelated Thoughts (TUTs) than in the following seconds, during attentive driving. It means that TUTs could have an impact on HR even on a 11s time-window. No difference has been found for heart rate variability indicators (RMSSD and pNN50). This result is not in line with Smallwood et al., (2004) since HR was found to be higher during TUTs. Such different results could be explained by differences in the dynamic of the tasks the participants had to achieve (computer task vs. driving). TUTs moments could consequently be distinguished from attentive moment (on-task thoughts) using heart rate. This potential distinction would be more effective by taking the kind of thoughts into account (see next section).

Behavioral data analysis showed that the gaze fixity was higher during TUTs than during attentive driving for on 11s time-window. As drivers' gaze is focused narrowly on the road ahead during TUTs, gaze fixity seems to be a sensitive indicator of TUTs. Our results, in line with He et al., (2011), showed that drivers' visual scanning is reduced their during TUTs. Moreover, it means that TUTs damage their road sides scanning leading to impaired information collection and processing coming from there. This could explain the part of the higher crash risk associated to TUTs and particularly to MW. Considering driving data, the vehicle speed appeared to be lower during TUTs episodes than after strengthening the impact of TUTs on drivers' behavior. So, in line with previous findings, TUTs should have an impact on drivers' behavior and physiological signals (Baird et al., 2011; He et al., 2011; Lemercier et 
al., 2014; Smallwood et al., 2004). In order to better understand such impact, it is necessary to categorize the kind of thought drivers are involved in. In the next part, the relative impact of each kind of thought is described by comparing the Stimulus Independent and Task-Unrelated Thoughts (SITUTs = MW) and Problem Solving Thoughts (PSTs).

\subsection{Comparisons between MW and PSTs signatures}

\subsubsection{Cardiac data}

Considering cardiac measurement, it appears that heart rate is significantly lower during MW than after being aware of it in the $[-5.5 \mathrm{~s} ;+5.5 \mathrm{~s}]$ temporal window. Such significance, which has not been highlighted in previous study, is due to a specific pattern in HR in seconds following participant's SR (Figure 1). This special pattern could be explained by the dynamic of the task in which drivers were involved. Indeed, participants were asked to be focus on the driving task and self-report their MW episodes. This means that in the seconds prior to self-reports, drivers were focused on their personal thoughts rather than driving. Thus, when they became aware of their inattentive state, corresponding to a gain in meta-consciousness (Schooler, 2002) participants declared their thought and were instructed to focus back on the driving task. However, MW impairs the working memory update (Kam, Nagamatsu, \& Handy, 2014) by drawing attentional resources from it to feed thoughts (Levinson, Smallwood, \& Davidson, 2012). This means that drivers could no longer be able to refresh their situational awareness, which corresponds to the state of knowledge about the elements in a dynamic environment (Endsley, 1995). Hence, as soon as they became aware of a wandering thought, drivers seemed to seek information (their speeds, the location of others vehicles etc...), processed it and integrated it to quickly recover a clear and accurate situational awareness. If they did so, they had to spend cognitive resources to shift between the default and the attentional mode (Yanko $\&$ Spalek, 2014). This switchover could have a cost in terms of attentional resources. Yet, a recent study has showed the feasibility of detecting the cognitive effort generating by a cognitive demand of a task through heart rate measurement (Pepin et al., 2017). It appears that the specific pattern found here after participants self-reported their MW episodes could correspond to a cognitive effort pattern. Time-windows used for this experiment and in Pepin et al., (2017) are similar. As previously explained, it seems likely that this increase in HR is responsible for the statistical significance highlighted here. The difference is therefore due to an increase in HR, which could come from a cognitive cost. This cognitive cost could have be necessary to shift from a wandering mode underlain by the default mode network (Christoff et al., 2009) to an attentive mode (Mason et al., 2007) underlain by the dorsal attentional network (Vincent et al., 2006) generating the special pattern in $[+1 \mathrm{~s} ;+4 \mathrm{~s}]$ following the SR.

The special pattern spelt out here is not present for the PST condition in the same time-window. Nevertheless, different fluctuations in HR have been highlighted between PSTs and attentive driving meaning that PSTs could have a cardiac signature while the only difference for the MW conditions have been found during the attentive driving period (Figure 1). Even if the difference for MW and PSTs is not significant regardless time-window (before and after), this cardiac pattern could be discussed regarding results outlined above. Indeed, the need to reorient our attention to driving could have generated a small cognitive effort, insufficient to reach 
significance. With a less refine environment and more vehicles, the reorientation of attention could have been more expensive in cognitive resources inducing a larger HR acceleration. The present study has not been able to highlight a cardiac signature of MW or PSTs but found that the reorientation of drivers' attention after a MW episode gets a cognitive cost that could be detectable by averaging heart rate values.

\subsubsection{Ocular behavior}

Considering oculometric measurement, the gaze fixity rate was higher during MW episodes than after. The difference is significant in the $[-5.5 \mathrm{~s} ;+5.5 \mathrm{~s}]$ time-window. Conversely, no difference has been found for PST conditions. Such results support the previous hypothesis in which the specific cardiac pattern is due to a need for drivers to reorient attention towards driving after a MW episodes. Indeed, drivers' gaze appeared to be fixed during MW episodes meaning that the amplitude of their visual scanning is reduced. Drivers do not seem to be as efficient to collect and process information as they were when focusing on driving. Hence, to update their situational awareness, drivers scanned the environment in a broader way after having self-reported their MW episodes (Figure 2). It has already been proven that MW leads to a reduction in drivers horizontal visual scanning (He et al., 2011) but an increase in drivers gaze fixity during MW means that drivers' gaze get stuck straight ahead. A parallel could be made with failure in attentional disengagement among aircraft pilots (Dehais et al., 2011). Indeed, MW could prevent attentional disengagement from drivers' thoughts to driving. This failure in attentional disengagement would lead to a staring gaze and then increase the risk of an accident.

Now, considering PST, no difference has been found for the gaze fixity rate. Such result might be the fact that 200 events were averaged to analyze MW while only 46 events have been averaged for PST (Figure 3). Still, it appears that there are substantial differences between MW and PST. Indeed, the gaze is more fixed during MW than during PST. More than $60 \%$ of drivers gaze during MW events were fixed in the second before the SR while it barely raise $45 \%$ for PSTs (it has to be noted that the gaze fixity baseline reaches 37\%). MW impact gaze behavior by reducing the visual scanning and generating an impaired visual attention while the gaze fixity seems to be non-sensitive to PSTs under current experimental conditions.

\subsubsection{Driving behavior}

Considering driving behavior, the vehicle speed tends to be lower during TUTs than during attentive driving moments. However, in the present study, vehicles' speed gradually increase while it has been shown to decrease while having off-task thoughts (Yanko \& Spalek, 2014). When having a closer look and taking into account the kind of thought, it appears that the vehicle speed is lower during MW than during attentive driving but tends to gradually increase up to approximately 1 second after drivers self-reported their wandering thoughts (Figure 4). It could correspond to the necessary time for drivers to reorient their attention towards driving, update information and rectify their speed. While drivers were asked to maintain the speed of their vehicle as close as possible to $70 \mathrm{~km}$ per hour, it seems that they did not have enough cognitive resources to be focus on their thoughts and control lateral and longitudinal positions of their vehicle. Drivers seemed to experience a failure in their executive control leading to 
higher speeds, which could partly explain the higher crash risk imputable to MW (Galera et al., 2012). Some reservations should be made with the present interpretation since only a trending effect have been highlighted.

504 Conversely, no statistical significance has been found for the vehicle speed between PSTs and attentive driving moments and between PST and MW for the vehicle lateral position, steering wheel angle or speed. Similarly, no statistical significance has been found after having TUTs, during attentive driving moments, for MW and PST conditions, meaning that the driving behavior seems to be affected by TUTs but globally unaffected by the intentionality of TUTs. Drivers were aware that they were having off-task thoughts during PSTs so they could have been able to set up strategies. Those strategies could have been absent for MW explaining that speed gradually increased at that time. The absence of statistical significance for the lateral position of the vehicle and the steering wheel angle could be partially explained by the presence of curves during driving sessions. Indeed, several events (self-report mind wandering and reflection upon innovation) happened during curves leading to high steering wheel angle values and high variation in the lateral positions values of the vehicle. These alterations of data occurred sometimes during TUTs and sometimes during attentive driving moments. To be able to conclude about the impact of the kind of thoughts on the lateral position of the vehicle and the steering wheel angle, the use of a different task with straight lines and no curve should have been used. To conclude about speed, it is also likely that the vehicle speed management is affected by MW while the lateral position and the steering wheel angle are not. Indeed, managing speed requires drivers a constant cognitive resources allocation management. To do so, drivers have to periodically check the speedometer, keep in mind the information and then adapt their behavior. Nevertheless, with an increase in the gaze fixity and an impossibility to update their working memory, drivers fail to process such information generating a perseverative behavior and a gradual speed increase. In conclusion, MW seems to impair drivers' executive control leading to a persistent behavior. During MW, drivers are no longer able to keep watch their speed. This could be problematic, especially under real driving conditions with strong time pressure (Merat, Jamson, Lai, Daly, \& Carsten, 2014).

\subsection{Conclusion}

The question of how various off-task thoughts might impact drivers is a topic of increasing concern not only for road safety but also for human performance and comprehension. The present study intended to make a distinction between intentional (PSTs) and unintentional (MW) thoughts. Being more specific about the features of thought allow to better understand inattention and to take effective countermeasures to ensure drivers' safety. The present study highlighted behavioral and physiological signatures of Task-Unrelated Thoughts (TUTs). During TUTs, the gaze fixity is higher and the speed of the vehicle is lower than during attentive driving moments. When taking the kind of thought into consideration, it appeared that heart rate and speed are affected by both MW and PSTs while the gaze fixity is only sensitive to MW. For this reason, the gaze fixity appeared as a sensitive indicator of MW. Indeed, MW draws on working memory resources (Kam et al., 2014) to trigger and feed self-generated thoughts (Levinson et al., 2012). MW and PSTs seem to have different oculometric signatures strengthening the need to distinguish the kind of thought when studying off-task thoughts. The 
following perseverative behavior and staring gaze prevent drivers to properly scan the environment. And even if they collect a part of available information, evidences coming from neurosciences have showed that sensory cortices are less active and information are less wellprocessed during MW (Smallwood, Beach, Schooler, \& Handy, 2008). Oculometric measurements should therefore be considered more closely when researchers study MW. Consistent with previous findings (McVay \& Kane, 2009; Smallwood, 2010), behavioral outcomes showing that gaze fixity and speed increase during TUTs unveil a failure in executive control and in resources allocation management. This leads to incapacity to both maintain TUTs and manage speed. Nevertheless, and this is the first limitation of the present study, changing the response mode between MW and PSTs add some variability in data which could explain this difference. Indeed, flashing headlights and say "stop" are two different output modes, which could have influence the gaze fixity. Secondly, MW and PST conditions were not averaged over the same number of events leading to more accurate interpretations and conclusions for MW than for PSTs. Moreover, when participants were asked to self-report their wandering thoughts we assume that we can only study MW that became, at a certain moment, conscious. Participants cannot report an unconscious wandering thought and can only wait for this thought to become conscious before being able to report it. This is why the present study only considered unintentional and, in the first place, unaware thoughts that became, at one time aware. Such off-task thoughts might be different from thoughts that would never become aware.

This study has not been capable to demonstrate strong differences between PST and MW. But recent findings seemed to direct research towards more specific thoughts features (Golchert et al., 2017) such as awareness (Smith et al., 2006), temporal focus (Smallwood \& Schooler, 2015), temporal distance (Spronken et al., 2016), emotional valence (Killingsworth \& Gilbert, 2010), relevance of the thought to the individual (Andrews-Hanna et al., 2013) and task demand (He et al., 2011). A better understanding of the respective impact of these features could be very useful to identify detrimental thoughts responsible for the "disruptive mind-wandering" state doubling the risk to be responsible for a car accident (Galera et al., 2012). But the importance of each factor is difficult to measure considering strong and winding links between them (Ruby, Smallwood, Engen, \& Singer, 2013; Smallwood \& Schooler, 2015; Stawarczyk et al., 2011). As it has been done with the intentionality in the present study, future research should therefore have to bring to light the impact of temporal focus, emotional valence and subjective relevance of the current thought, which seem to be the most promising thought features to explain that MW while driving is detrimental or not. Indeed, it seems that the temporality and the occurrence of MW are related: the more people have future-oriented thoughts, the more they wander (Baird et al., 2011). It also seems that emotional valence and temporality are linked (Smallwood \& Schooler, 2015) and a bidirectional relationship between negative emotion and MW have been highlighted (Smallwood \& Schooler, 2015; Techer, 2016). When we consider that the emotional valence of off-task thoughts affect cognitive performances (Banks, Welhaf, Hood, Boals, \& Tartar, 2016), all mind wandering seem not be equal. Considering links between temporality and other thoughts features, it is therefore highly likely that the content of a wandering thought and particularly its temporality seems promising to explain a higher disruptive effect on drivers (Lemercier et al., 2014). 
585 Finally, once links between thoughts features and their impacts on drivers will be questioned 586 and spelled out, a detection algorithm of MW could be developed. The idea is to use the gaze 587 fixity and others relevant behavioral (e.g., deviations in the vehicle's lateral position: Lemercier 588 et al., 2015) and physiological (e.g., pupil dilation: Konishi et al., 2017) indicators to assess the 589 presence of MW. The final objective being to merge it together to improve the ability of an 590 algorithm to spot MW when it is disruptive. To do so, the selected indicators must be evaluated 591 on their sensitivity, specificity and robustness. It could be also possible to take into account the 592 driving context to better prevent car crash risk. The objective is to monitor drivers' attentional 593 states and pinpoint times when driver's mind dangerously drifts away. Such solution is entirely 594 in continuation with work achieved years ago on distraction using a layered algorithm, dynamic 595 bayesian networks and supervised clustering (Liang et al., 2007; Liang \& Lee, 2014). It is 596 therefore critical to collect both physiological and behavioral data to expend our understanding 597 of MW through a data triangulation method, use these data mining methodologies to detect MW 598 while driving and then still improve road safety.

599 Conflict of interest

600 All authors declare they have no conflict of interest 
Andrews-Hanna, J. R., Kaiser, R. H., Turner, A. E., Reineberg, A., Godinez, D., Dimidjian, S., \& Banich, M. (2013). A penny for your thoughts: dimensions of self-generated thought

604

605

606

607

608

609

610 content and relationships with individual differences in emotional wellbeing. Frontiers in psychology, 4, 900.

Baird, B., Smallwood, J., \& Schooler, J. W. (2011). Back to the future: autobiographical planning and the functionality of mind-wandering. Consciousness and Cognition, 20(4), 1604-1611. https://doi.org/10.1016/j.concog.2011.08.007

Banks, J. B., Welhaf, M. S., Hood, A. V. B., Boals, A., \& Tartar, J. L. (2016). Examining the role of emotional valence of mind wandering: All mind wandering is not equal. Consciousness and Cognition, 43, 167-176. https://doi.org/10.1016/j.concog.2016.06.003

Berthié, G., Lemercier, C., Paubel, P.-V., Cour, M., Fort, A., Galéra, C., ... Maury, B. (2015). The restless mind while driving: drivers' thoughts behind the wheel. Accident; Analysis and Prevention, 76, 159-165. https://doi.org/10.1016/j.aap.2015.01.005

Bixler, R., \& D’Mello, S. (2014). Toward Fully Automated Person-Independent Detection of Mind Wandering. In V. Dimitrova, T. Kuflik, D. Chin, F. Ricci, P. Dolog, \& G. J. Houben (Éd.), User Modeling, Adaptation, and Personalization, Umap 2014 (Vol. 8538, p. 37-48). Berlin: Springer-Verlag Berlin.

Braboszcz, C., \& Delorme, A. (2011). Lost in thoughts: neural markers of low alertness during mind wandering. NeuroImage, 54(4), 3040-3047.

https://doi.org/10.1016/j.neuroimage.2010.10.008

Brown, I. D. (2005). Review of the «looked but failed to see » accident causation factor. Consulté à l'adresse https://trid.trb.org/view/1156399

Burdett, B. R. D., Charlton, S. G., \& Starkey, N. J. (2016). Not all minds wander equally: The influence of traits, states and road environment factors on self-reported mind wandering during everyday driving. Accident; Analysis and Prevention, 95(Pt A), 1-7. https://doi.org/10.1016/j.aap.2016.06.012

Chaparro, R. A. H. (2015, novembre 9). Behavioral and neural correlates of spontaneous attentional decoupling : towards an understanding of mind wandering (phdthesis). Université Pierre et Marie Curie - Paris VI. Consulté à l'adresse https://tel.archives-ouvertes.fr/tel01314225/document

Christoff, K., Gordon, A. M., Smallwood, J., Smith, R., \& Schooler, J. W. (2009). Experience sampling during fMRI reveals default network and executive system contributions to mind wandering. Proceedings of the National Academy of Sciences, 106(21), 8719-8724. https://doi.org/10.1073/pnas.0900234106

Corballis, M. C. (2013). Wandering tales: evolutionary origins of mental time travel and language. Frontiers in Psychology, 4. https://doi.org/10.3389/fpsyg.2013.00485 
Dehais, F., Causse, M., \& Tremblay, S. (2011). Mitigation of Conflicts with Automation: Use of Cognitive Countermeasures. Human Factors, 53(5), 448-460. https://doi.org/10.1177/0018720811418635

Endsley, M. R. (1995). Toward a theory of situation awareness in dynamic systems. Human factors, 37(1), 32-64.

Galera, C., Orriols, L., M'Bailara, K., Laborey, M., Contrand, B., Ribereau-Gayon, R., ... Lagarde, E. (2012). Mind wandering and driving: a responsibility case-control study. $B M J$ British medical journal, 345, 7 p. https://doi.org/10.1136/bmj.e8105

Golchert, J., Smallwood, J., Jefferies, E., Seli, P., Huntenburg, J. M., Liem, F., ... Margulies, D. S. (2017). Individual variation in intentionality in the mind-wandering state is reflected in the integration of the default-mode, fronto-parietal, and limbic networks. NeuroImage, 146, 226-235. https://doi.org/10.1016/j.neuroimage.2016.11.025

Gonçalves, Ó. F., Rêgo, G., Oliveira-Silva, P., Leite, J., Carvalho, S., Fregni, F., ... Boggio, P. S. (2017). Mind wandering and the attention network system. Acta Psychologica, 172, 49-54. https://doi.org/10.1016/j.actpsy.2016.11.008

Greicius, M. D., Krasnow, B., Reiss, A. L., \& Menon, V. (2003). Functional connectivity in the resting brain: A network analysis of the default mode hypothesis. Proceedings of the National Academy of Sciences of the United States of America, 100(1), 253-258. https://doi.org/10.1073/pnas.0135058100

He, J., Becic, E., Lee, Y.-C., \& McCarley, J. S. (2011). Mind wandering behind the wheel: performance and oculomotor correlates. Human Factors, 53(1), 13-21. https://doi.org/10.1177/0018720810391530

Kam, J. W. Y., Nagamatsu, L. S., \& Handy, T. C. (2014). Visual asymmetry revisited: Mind wandering preferentially disrupts processing in the left visual field. Brain and Cognition, 92C, 32-38. https://doi.org/10.1016/j.bandc.2014.10.002

Killingsworth, M. A., \& Gilbert, D. T. (2010). A Wandering Mind Is an Unhappy Mind. Science, 330(6006), 932-932. https://doi.org/10.1126/science.1192439

Konishi, M., Brown, K., Battaglini, L., \& Smallwood, J. (2017). When attention wanders: Pupillometric signatures of fluctuations in external attention. Cognition, 168, 16-26.

Kopp, K., D’Mello, S., \& Mills, C. (2015). Influencing the occurrence of mind wandering while reading. Consciousness and Cognition, 34, 52-62.

https://doi.org/10.1016/j.concog.2015.03.003

Lemercier, C., Pêcher, C., Berthié, G., Valéry, B., Vidal, V., Paubel, P.-V., ... Maury, B. (2014). Inattention behind the wheel: How factual internal thoughts impact attentional control while driving. Safety Science, 62, 279-285. https://doi.org/10.1016/j.ssci.2013.08.011 
673 Levinson, D. B., Smallwood, J., \& Davidson, R. J. (2012). The Persistence of Thought:

674 Evidence for a Role of Working Memory in the Maintenance of Task-Unrelated Thinking.

675 Psychological Science, 23(4), 375-380. https://doi.org/10.1177/0956797611431465

676 Liang, Y., \& Lee, J. D. (2014). A hybrid Bayesian Network approach to detect driver 677 cognitive distraction. Transportation Research Part C: Emerging Technologies, 38, 146-155. 678 https://doi.org/10.1016/j.trc.2013.10.004

679 Liang, Y., Reyes, M. L., \& Lee, J. D. (2007). Real-Time Detection of Driver Cognitive 680 Distraction Using Support Vector Machines. IEEE Transactions on Intelligent Transportation 681 Systems, 8(2), 340-350. https://doi.org/10.1109/TITS.2007.895298

682 McVay, J. C., \& Kane, M. J. (2009). Conducting the Train of Thought: Working Memory 683 Capacity, Goal Neglect, and Mind Wandering in an Executive-Control Task. Journal of 684 experimental psychology. Learning, memory, and cognition, 35(1), 196-204.

685 https://doi.org/10.1037/a0014104

686 Merat, N., Jamson, A. H., Lai, F. C. H., Daly, M., \& Carsten, O. M. J. (2014). Transition to 687 manual: Driver behaviour when resuming control from a highly automated vehicle.

688 Transportation Research Part F: Traffic Psychology and Behaviour, 27, 274-282.

689 https://doi.org/10.1016/j.trf.2014.09.005

690 Mooneyham, B. W., \& Schooler, J. W. (2013). The Costs and Benefits of Mind-Wandering:

691 A Review. Canadian Journal of Experimental Psychology-Revue Canadienne De Psychologie 692 Experimentale, 67(1), 11-18. https://doi.org/10.1037/a0031569

693 Mosedale, J., Purdy, A., \& Clarkson, E. (2004). Contributory factors to road accidents.

694 Consulté à l'adresse https://trid.trb.org/view/864416

695 Ottaviani, C., Shahabi, L., Tarvainen, M., Cook, I., Abrams, M., \& Shapiro, D. (2014).

696 Cognitive, behavioral, and autonomic correlates of mind wandering and perseverative 697 cognition in major depression. Frontiers in Neuroscience, 8, 433.

698 https://doi.org/10.3389/fnins.2014.00433

699 Parasuraman, R. (2003). Neuroergonomics: Research and practice. Theoretical issues in 700 ergonomics science, 4(1-2), 5-20.

701 Pepin, G., JALLAIS, C., Fort, A., Moreau, F., Navarro, J., \& GABAUDE, C. (2017).

702 Towards real-time detection of cognitive effort in driving: contribution of cardiac

703 measurement. Le travail humain, 80, 51-72. https://doi.org/10.3917/th.801.0051

704 Raichle, M. E., MacLeod, A. M., Snyder, A. Z., Powers, W. J., Gusnard, D. A., \& Shulman, 705 G. L. (2001). A default mode of brain function. Proceedings of the National Academy of 706 Sciences of the United States of America, 98(2), 676-682.

707 Rayner, K. (1998). Eye movements in reading and information processing: 20 years of 708 research. Psychological Bulletin, 124(3), 372-422. https://doi.org/10.1037/0033-

$709 \quad 2909.124 .3 .372$ 
710 Regan, M. A., \& Strayer, D. L. (2014). Towards an Understanding of Driver Inattention:

711 Taxonomy and Theory. Annals of Advances in Automotive Medicine, 58, 5-14.

712 Roy, R. N. (2015, juin 4). Étude de corrélats électrophysiologiques pour la discrimination

713 d'états de fatigue et de charge mentale: apports pour les interfaces cerveaumachine passives

714 (phdthesis). Université Grenoble Alpes. Consulté à l'adresse https://tel.archives-

715 ouvertes.fr/tel-01217465/document

716 Ruby, F. J. M., Smallwood, J., Engen, H., \& Singer, T. (2013). How self-generated thought

717 shapes mood--the relation between mind-wandering and mood depends on the socio-temporal

718 content of thoughts. PloS One, 8(10), e77554. https://doi.org/10.1371/journal.pone.0077554

719 Schooler, J. W. (2002). Re-representing consciousness: dissociations between experience and

720 meta-consciousness. Trends in Cognitive Sciences, 6(8), 339-344.

721 https://doi.org/10.1016/S1364-6613(02)01949-6

722 Schooler, J. W., \& Schreiber, C. A. (2004). Experience, meta-consciousness, and the paradox 723 of introspection. Journal of Consciousness Studies, 11(7-8), 17-39.

724 Seli, P., Ralph, B. C. W., Konishi, M., Smilek, D., \& Schacter, D. L. (2017). What did you

725 have in mind? Examining the content of intentional and unintentional types of mind

726 wandering. Consciousness and Cognition, 51, 149-156.

727 https://doi.org/10.1016/j.concog.2017.03.007

728 Seth, A. K., Dienes, Z., Cleeremans, A., Overgaard, M., \& Pessoa, L. (2008). Measuring 729 consciousness: relating behavioural and neurophysiological approaches. Trends in Cognitive

730 Sciences, 12(8), 314-321. https://doi.org/10.1016/j.tics.2008.04.008

731 Smallwood, J. (2010). Why the global availability of mind wandering necessitates resource

732 competition: Reply to McVay and Kane (2010).

733 Smallwood, J. (2013). Distinguishing how from why the mind wanders: a process-occurrence 734 framework for self-generated mental activity. Psychological Bulletin, 139(3), 519-535.

735 https://doi.org/10.1037/a0030010

736 Smallwood, J., Beach, E., Schooler, J. W., \& Handy, T. C. (2008). Going AWOL in the brain: 737 mind wandering reduces cortical analysis of external events. Journal of Cognitive

738 Neuroscience, 20(3), 458-469. https://doi.org/10.1162/jocn.2008.20037

739 Smallwood, J., Davies, J. B., Heim, D., Finnigan, F., Sudberry, M., O’Connor, R., \&

740 Obonsawin, M. (2004). Subjective experience and the attentional lapse: task engagement and 741 disengagement during sustained attention. Consciousness and Cognition, 13(4), 657-690.

742 https://doi.org/10.1016/j.concog.2004.06.003

743 Smallwood, J., McSpadden, M., \& Schooler, J. W. (2008). When attention matters: The

744 curious incident of the wandering mind. Memory \& Cognition, 36(6), 1144-1150. 
Smallwood, J., \& Schooler, J. W. (2015). The science of mind wandering: empirically navigating the stream of consciousness. Annual Review of Psychology, 66, 487-518. https://doi.org/10.1146/annurev-psych-010814-015331

Smallwood, J., Schooler, J. W., Turk, D. J., Cunningham, S. J., Burns, P., \& Macrae, C. N. (2011). Self-reflection and the temporal focus of the wandering mind. Consciousness and Cognition, 20(4), 1120-1126. https://doi.org/10.1016/j.concog.2010.12.017

Smith, R., Keramatian, K., Smallwood, J., Schooler, J., Luus, B., \& Christoff, K. (2006). Mind-wandering with and without awareness: An fMRI study of spontaneous thought processes. In Proceedings of the Annual Meeting of the Cognitive Science Society (Vol. 28).

Spronken, M., Holland, R. W., Figner, B., \& Dijksterhuis, A. (2016). Temporal focus, temporal distance, and mind-wandering valence: Results from an experience sampling and an experimental study. Consciousness and Cognition, 41, 104-118.

https://doi.org/10.1016/j.concog.2016.02.004

Stawarczyk, D., Cassol, H., \& D’Argembeau, A. (2013). Phenomenology of future-oriented mind-wandering episodes. Frontiers in Psychology, 4, 425.

https://doi.org/10.3389/fpsyg.2013.00425

Stawarczyk, D., Majerus, S., Maj, M., Van der Linden, M., \& D’Argembeau, A. (2011). Mind-wandering: Phenomenology and function as assessed with a novel experience sampling method. Acta Psychologica, 136(3), 370-381. https://doi.org/10.1016/j.actpsy.2011.01.002

Techer, F. (2016, novembre 3). Impact de la colère sur l'attention, le traitement de l'information et les performances en conduite simulée (phdthesis). Université de Nantes. Consulté à l'adresse https://hal.archives-ouvertes.fr/tel-01455218/document

Vincent, J. L., Snyder, A. Z., Fox, M. D., Shannon, B. J., Andrews, J. R., Raichle, M. E., \& Buckner, R. L. (2006). Coherent spontaneous activity identifies a hippocampal-parietal memory network. Journal of Neurophysiology, 96(6), 3517-3531.

\section{https://doi.org/10.1152/jn.00048.2006}

Ward, A. F., \& Wegner, D. M. (2013). Mind-blanking: when the mind goes away. Frontiers in Psychology, 4. https://doi.org/10.3389/fpsyg.2013.00650

Yanko, M. R., \& Spalek, T. M. (2014). Driving with the wandering mind: the effect that mind-wandering has on driving performance. Human Factors, 56(2), 260-269. https://doi.org/10.1177/0018720813495280 